\title{
A Chromosome Atlas of the Genus Dactylis (Part two)
}

\author{
Martin Borrill and C. P. Carroll \\ Welsh Plant Breeding Station, Aberystwyth, Great Britain
}

Received August 27, 1967

\section{Foreword}

The geographical distribution of chromosome races in the genus Dactylis L. has been the subject of an extended survey in the search for new sources of genetic variation in this economically important herbage grass. Some 400 populations of wild Dactylis for the most part grown from seed derived from the indigenous vegetation of Europe, W. Asia and the Mediterranean have been grown at Aberystwyth for observation as spaced plants. Chromosomes were counted in sample plants from each of these, usually at first meiotic metaphase. The data pertaining to half of the collection have already been presented (Jones, Carroll and Borrill 1961). A similar format has been adopted for the information obtained subsequently, and the results are given here in the form of a map supported by a detailed list of localities.

\section{The distribution of Dactylis}

The general distributional features of Dactylis were discussed in the first article. The present data confirm and extend this pattern. Tetraploids are the predominant form in the group.

In regions of Mediterranean climate $D$. glomerata ssp. hispanica is the principal type, and amongst new localities, the Tunisian region is included for the first time. Further stations are reported in Portugal for the Mediterranean coastal D. marina which has also been found at Cap Serrat in Tunisia (Map 368). The verified distribution of temperate ssp. glomerata has been extended, especially in N. Spain and France. The two chromosome atlas maps taken together summarize the distributional information at the present time.

Diploid material accounts for perhaps $5 \%$ of all wild Dactylis. These diploids occur somewhat sporadically throughout the area of distribution of the tetraploids. Individual diploid subspecies, though they may be small in numbers of individuals and restricted in distribution, are of considerable genetic interest since they are the surviving relatives of the ancestors of the whole group (Fig. 1).

The tetraploid D. marina, which has a distinctive phenotype and is limited to coasts in the Mediterranean-subtropical area of distribution, has obvious affinities with diploids in the same region, notably ssp. smit' ii, ibizensis

1 Scottish Plant Breeding Station, Pentlandfield, Roslin, Midlothian, Great Britain. 


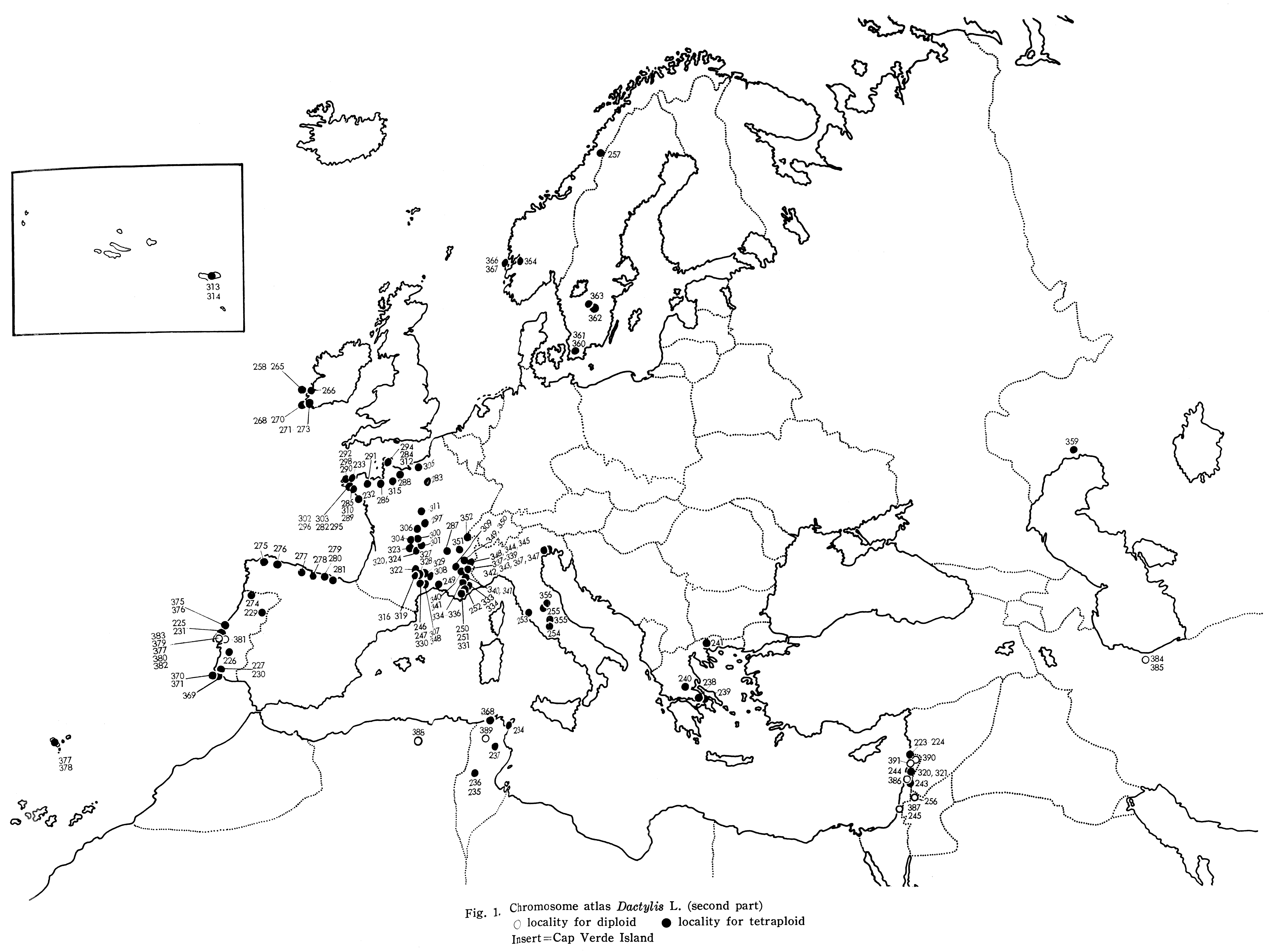




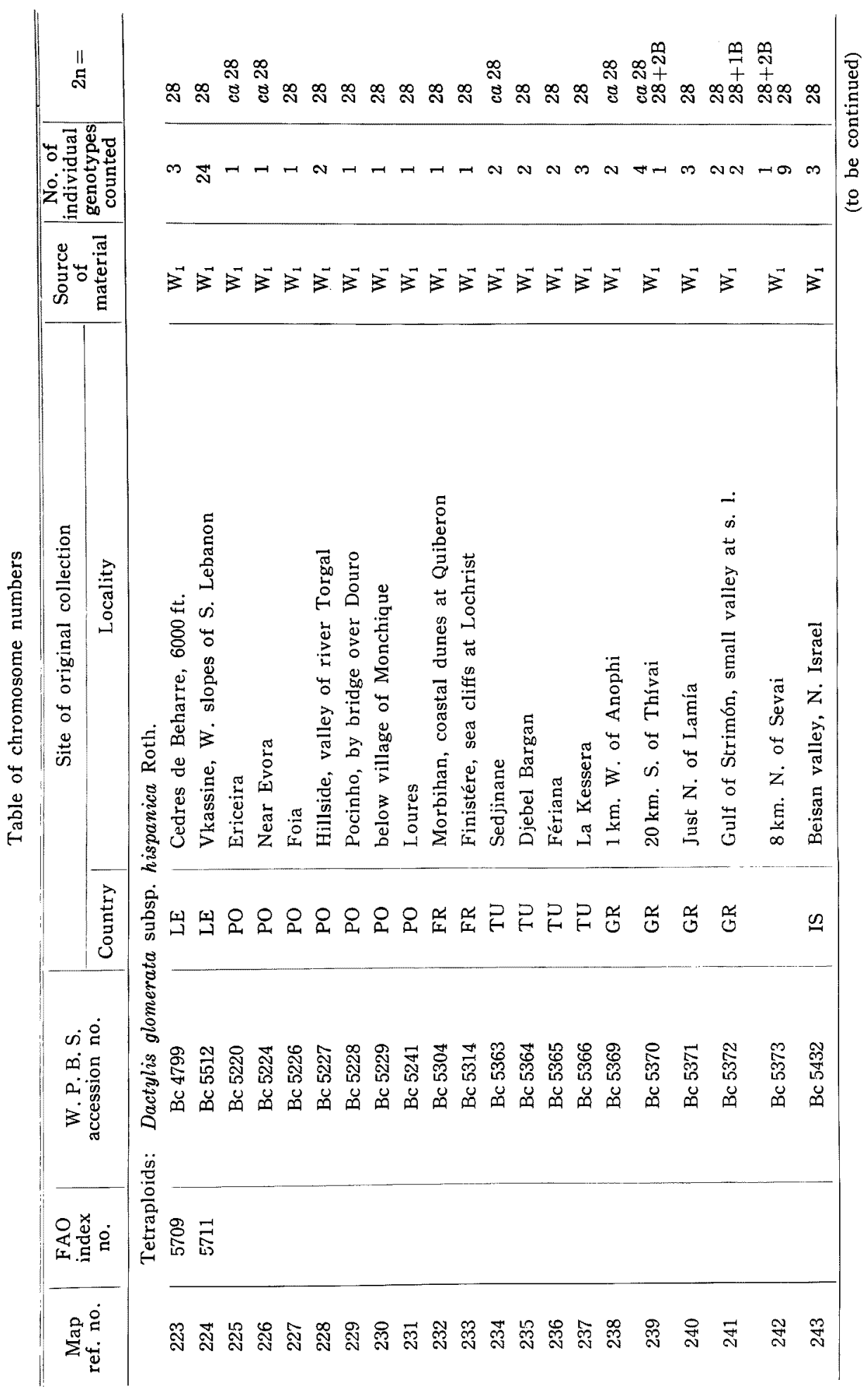




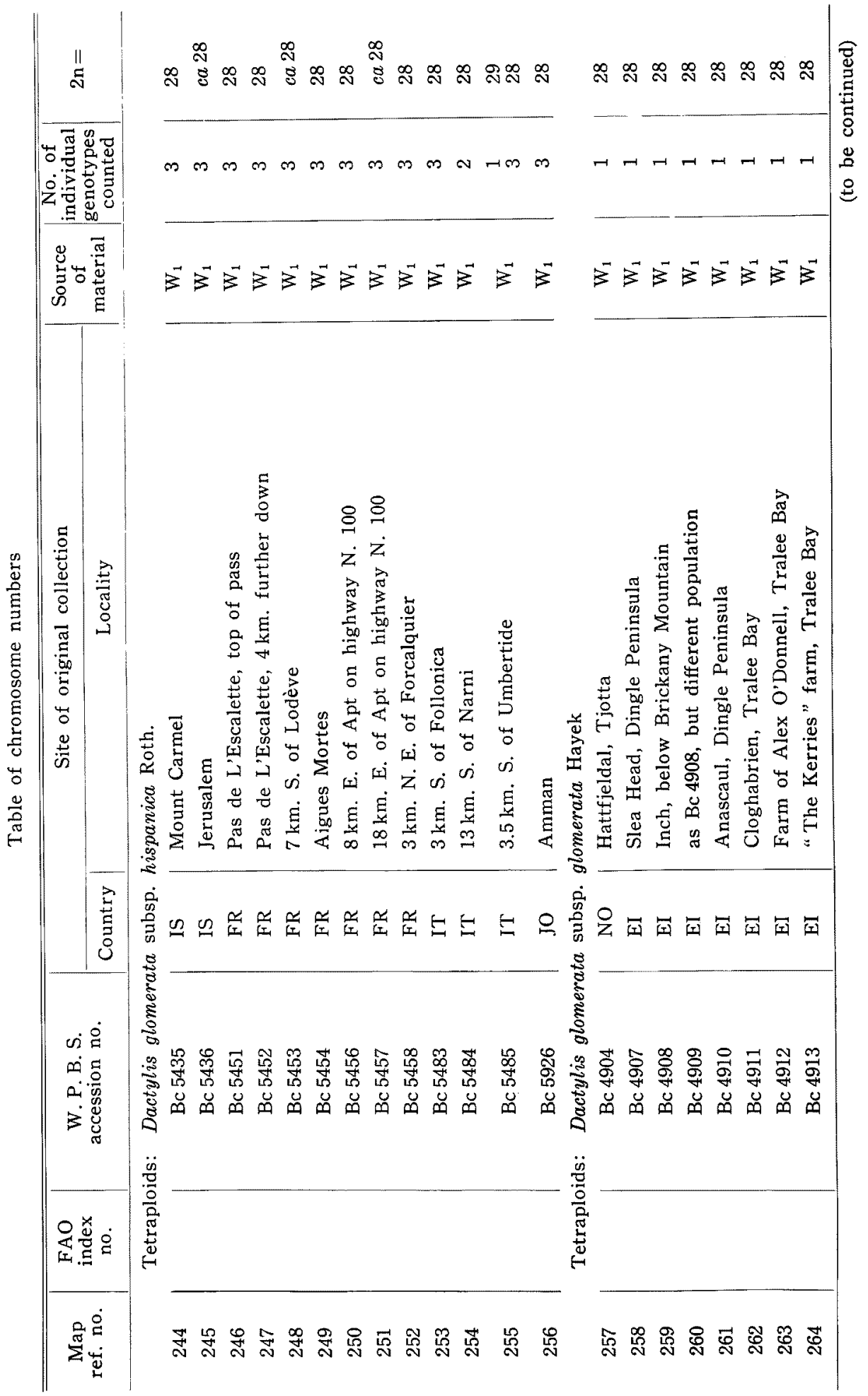




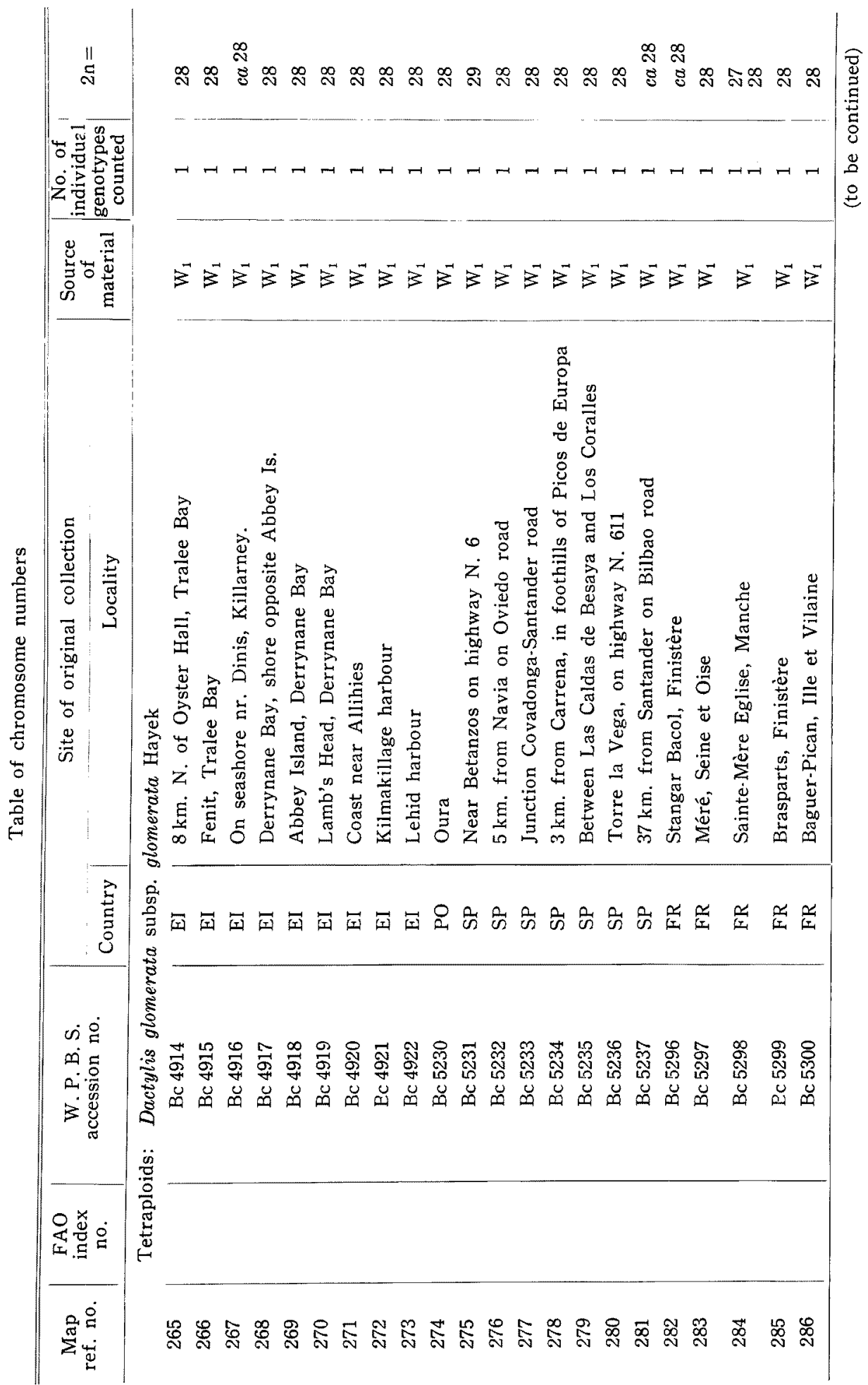




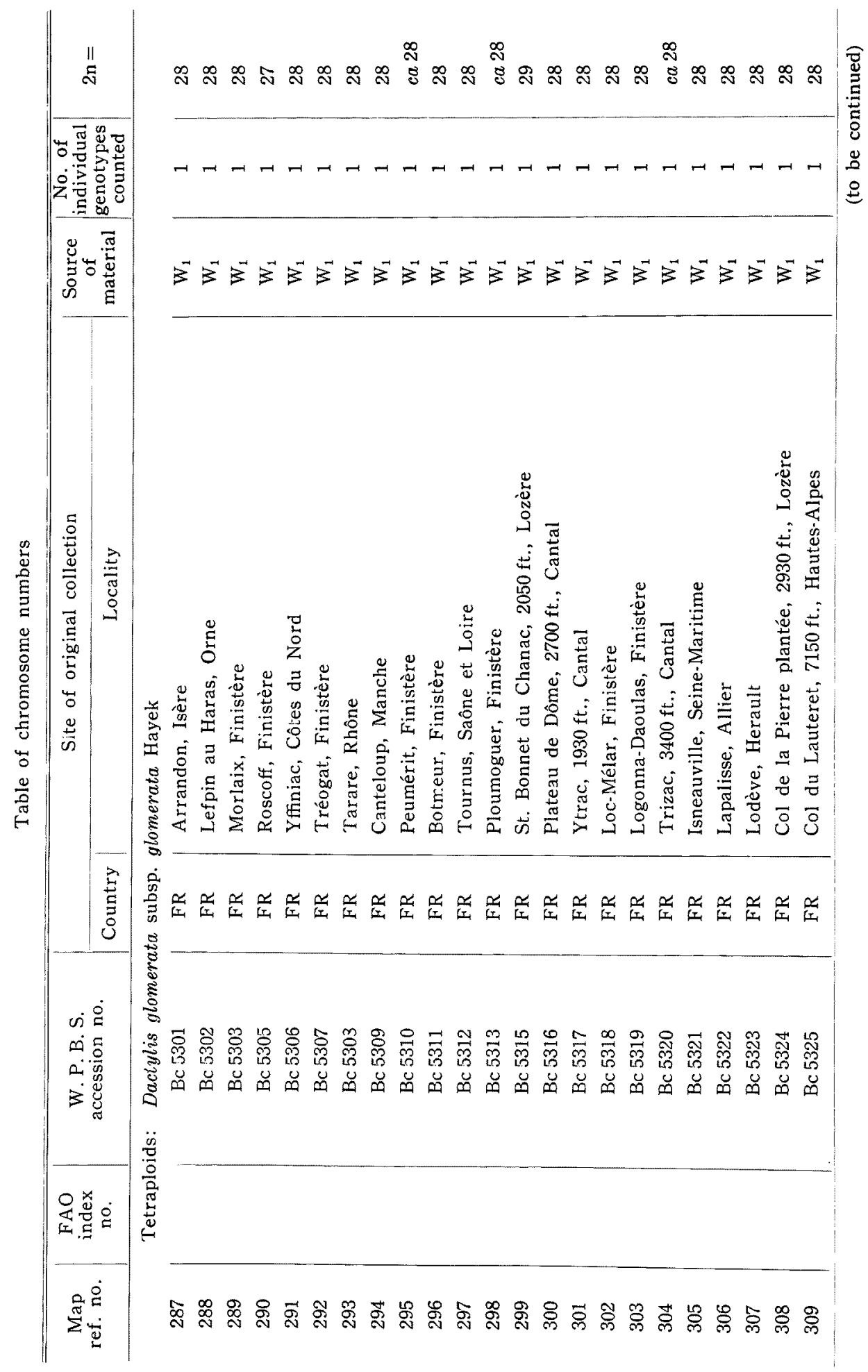




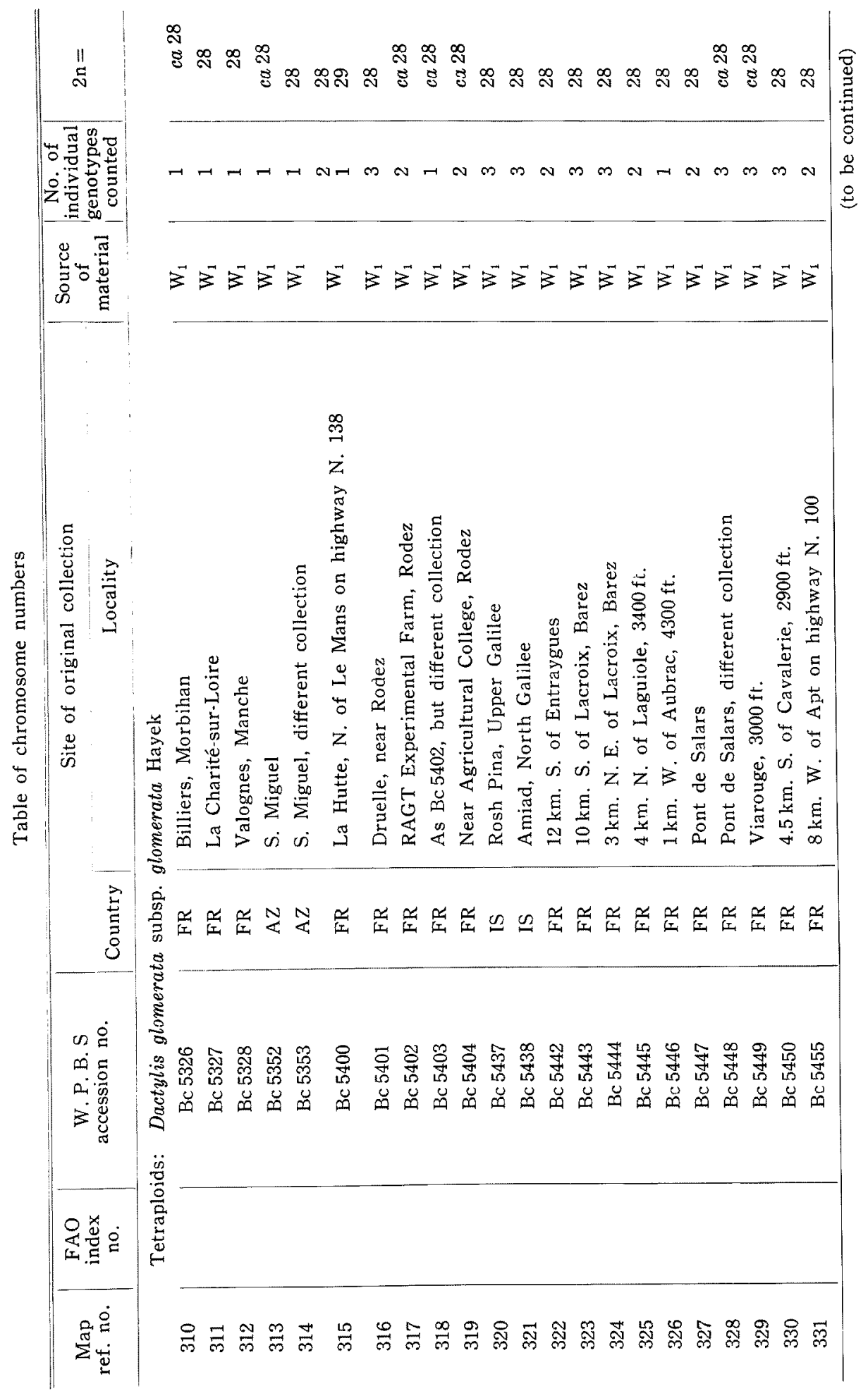




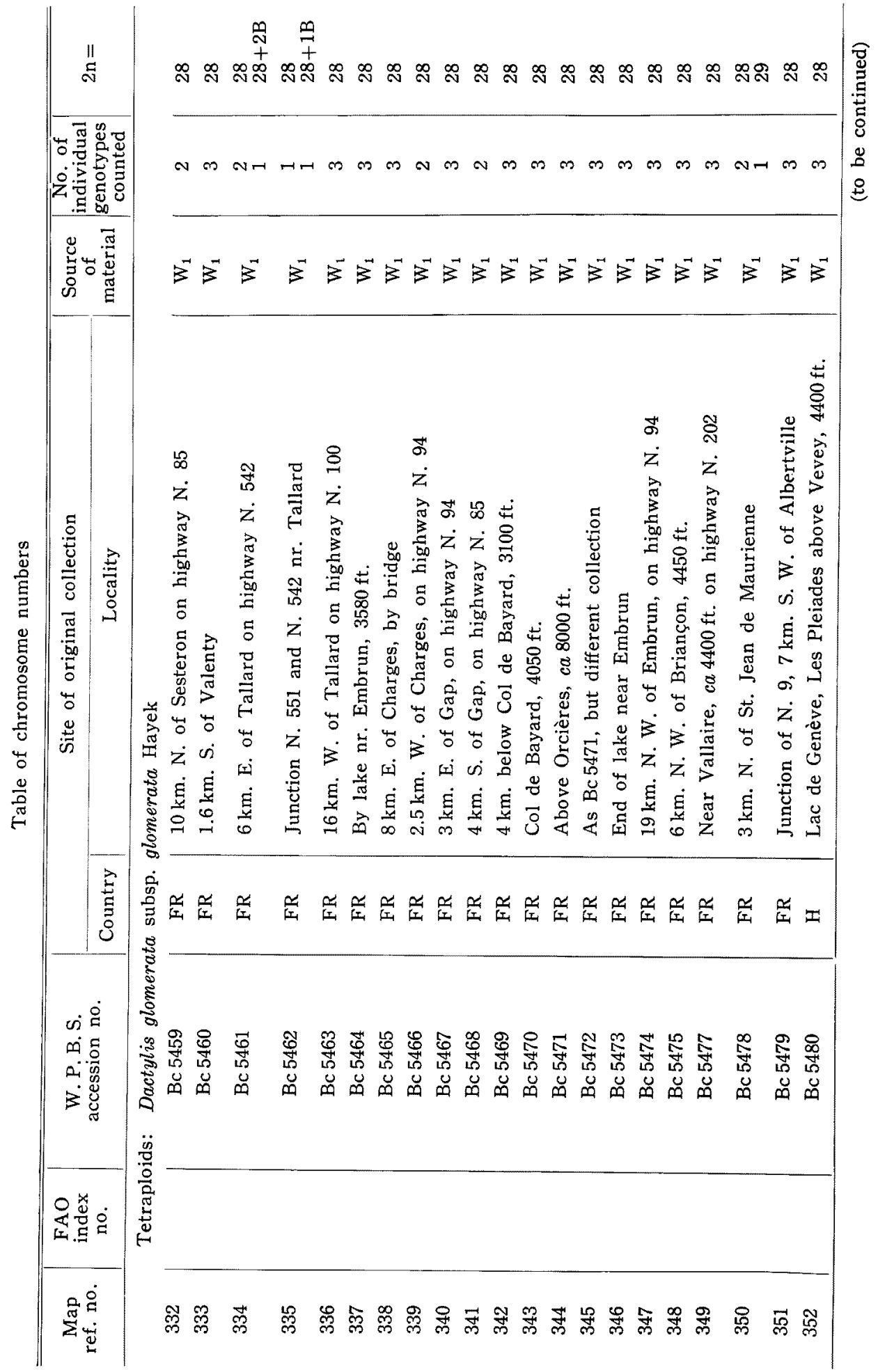




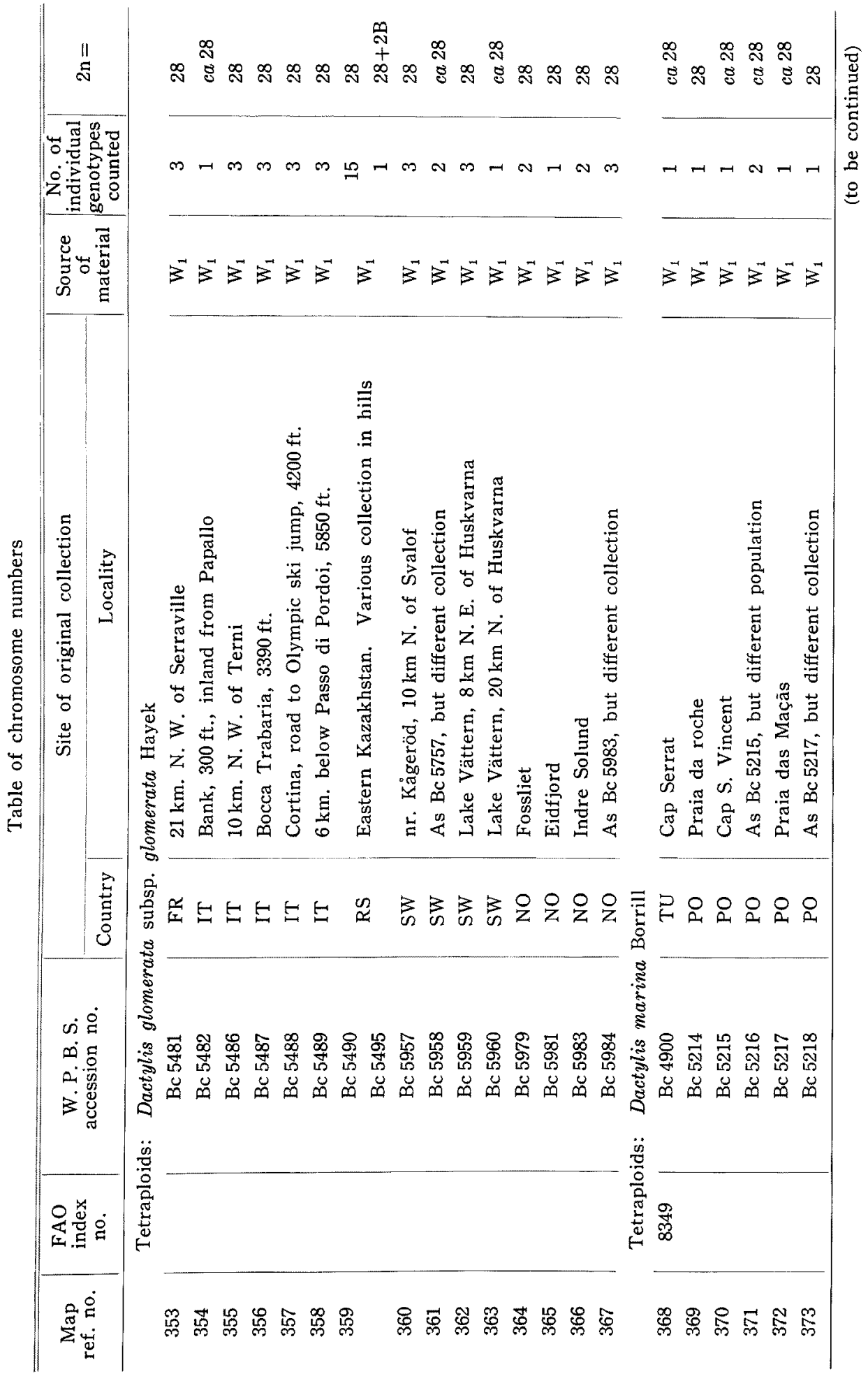




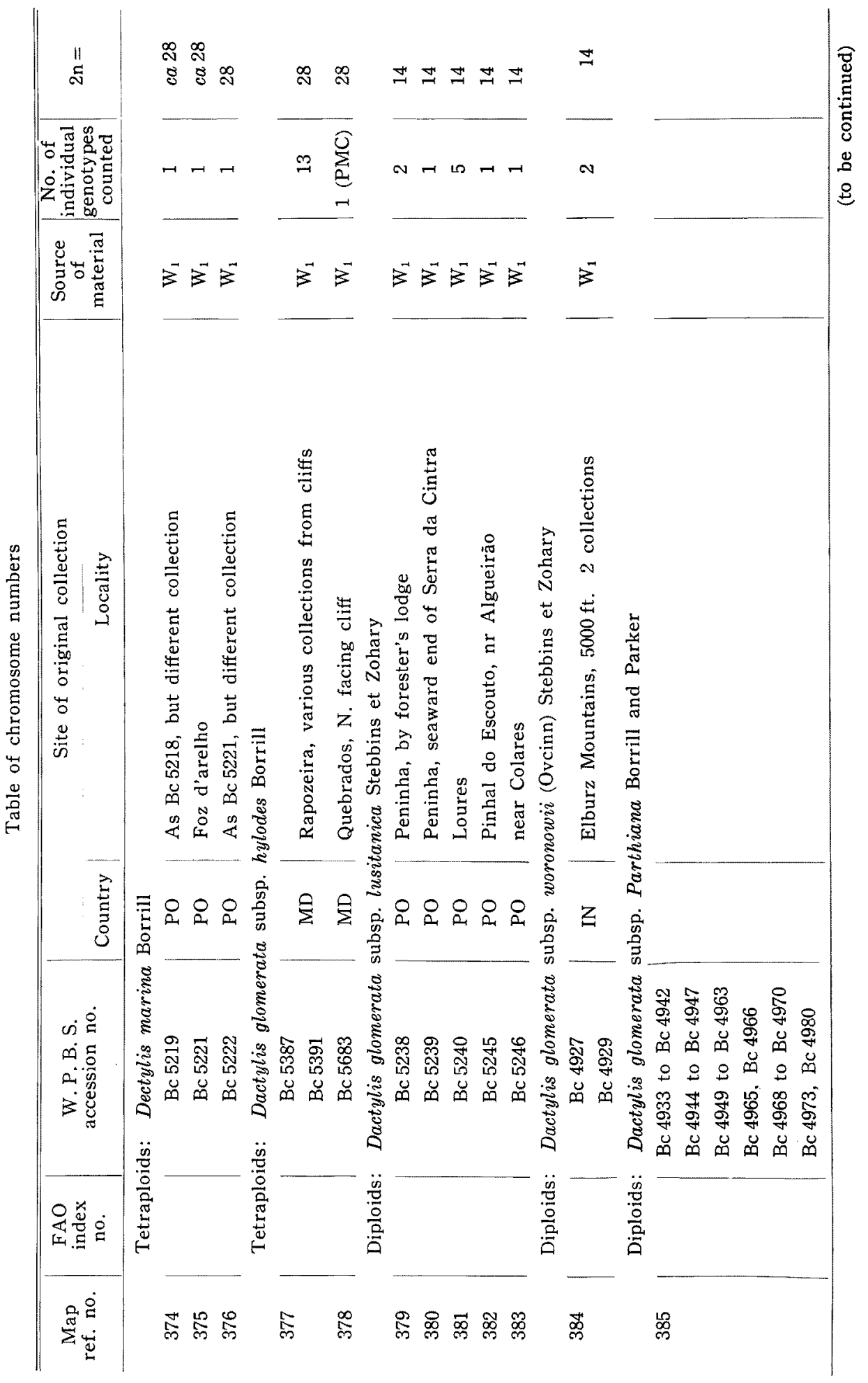




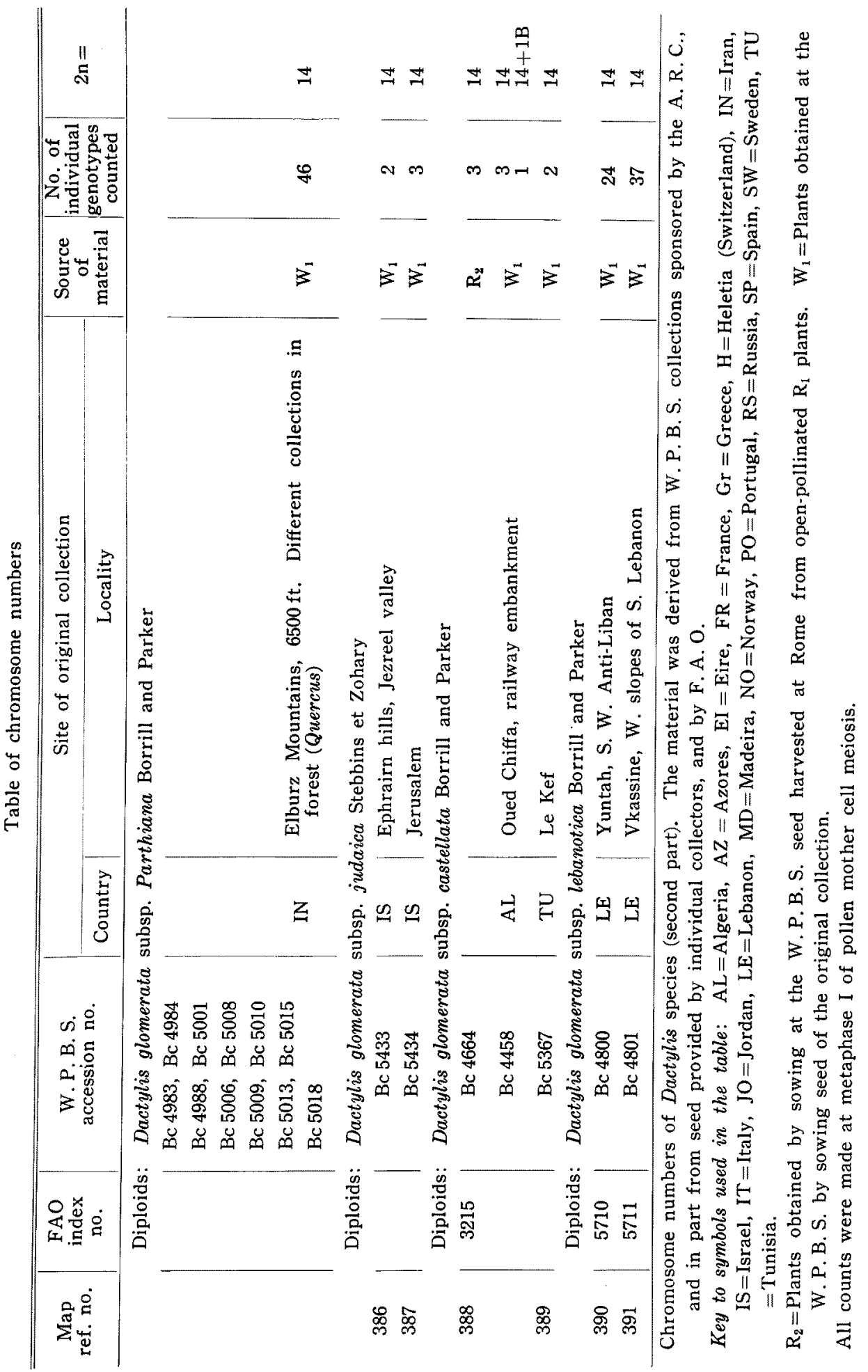


and santi (Benson 1966). The chromosomal survey has revealed a new tetraploid subsp. hylodes (Parker and Borrill, in preparation). This grass, which occurs on the island of Madeira, shows obvious morphological affinities (persistent, trailing perennial woody stems, leaf papillosity) to subsp. smithii, indigenous to the Canary Islands. Intensive collections on Madeira showed that smithii does not occur there. Populations similar in type, but not morphologically identical with smithii are known from the Cap Verde islands (herb. material). The possibility that ssp. hylodes may occur on islands other than Madeira needs investigating.

There is now evidence of two tetraploids with a subtropical-orientated distribution: hylodes very closely allied to smithii, and probably confined to Macaronesia, and $D$. marina having a more extended distribution in the coastal habitats of these islands, the Mediterranean, and the Atlantic coast of Portugal, north almost to Vigo.

Further collections have been examined in the diploid subspecies described by Stebbins and Zohary (1959), namely judaica, lusitanica, and woronowii. An extended range of counts has been made on material which, though included in the first map (1961), has now been given subspecific rank, namely castellata from Algeria, and lebanotica from the Lebanon.

An extended collection of Dactylis from the Elburz Mountains of N. Iran proved to be diploid (map 385) subspecies parthiana. This large-growing cocksfoot with temperate climate affinities occurs extensively in oak woods at the higher altitudes. Subspecies castellata, lebanotica, parthiana and hylodes are being described by Parker and Borrill.

Areas of contact between dissimilar geographical subspecies, and between diploids and tetraploids have been found during this survey. Both these situations are of interest. Hybridization between somewhat dissimilar, but more or less interfertile, geographical diploids, followed by chromosome doubling, has been postulated as the mode of origin of the tetraploids, many of which combine the characteristics of two or more diploid subspecies (Jones, Borrill and Carroll 1961). The best documented example of contact between diploids occurs in the Elburz range. Subspecies roronowii was found on dry, base-rich limestone outcrops in open thorn scrub at about $5000 \mathrm{ft}$. With increasing altitude a zone containing hybrid plants was found, followed by Quercus woodland, in which subsp. partitiana was a major component of the ground flora. These woodlands, at up to $6500 \mathrm{ft}$, were more humid, receiving precipitation from low cloud and mist even in the summer.

Contact between diploid and tetraploid (subsp. hispanica) in natural habitats has been found on several occasions: subsp. lusitanica at Loures, Portugal (map 381, 231), subsp. castellata at Oued Chiffa, Algeria (map 17, 1961), subsp. lebanotica at Yuntah and Vkassine, Lebanon (map. 390, 391, 224 ; map 98, 99, 1961), and subsp. judaica at Safad, Galilee (map 215, 1961). In the latter locality some 2000 plants in two contact areas were screened to find individuals with non-dehiscent anthers (a characteristic of triploid Dactylis). 
Out of 24 such plants with chromosomes counted, seven were found to be triploid (Zohary and Nur 1959).

No triploids have been found amongst the seedling progeny of diploid and tetraploid plants sampled at the other localities, though a deliberate search in the actual habitats might well have discovered some. These areas of diploid/tetraploid contact are of importance because of the opportunities for enrichment of the tetraploids by genes from the diploid. The triploids act as a one way bridge for gene flow from diploid to tetraploid (Zohary and Nur 1958, Jones and Borrill 1962).

Further investigation shows that, over a range of experimental reciprocal crosses between diploid and tetraploid Dactylis, tetraploid hybrid progeny were produced in numbers equalling the triploids (Carroll and Borrill 1965). Such tetraploid hybrids have a regular meiosis and normal fertility. No doubt, hybrids formed in this way were present in the contact areas sampled by Zohary and Nur, but were not discovered because of the prescreening practised for anther sterility. Indeed, in this area, where both chromosome races were morphologically very similar, tetraploid hybrids could have been identified positively only amongst the progeny of diploid female parents. The genetics and possible modes of origin of such tetraploid hybrids have been considered in detail in an earlier publication (Carroll and Borrill loc. cit.). Viewed on an evolutionary time-scale, the possibilities of gene-flow from the diploid to the tetraploid level via fertile $F_{1}$ hybrids are considerable. The capacity for forming tetraploid as well as triploid hybrids represents an important increase in genetic versatility in the genus. By such crosses the complex hybridity often found in wild tetraploid Dactylis could be supported and extended. Dactylis is now chromosomally very well documented, and all the levels of polyploidy which exist have probably been found. The distribution of diploids and tetraploids in particular areas would justify further study, on the one hand amongst the subtropical forms of Macaronesia, and on the other in contact regions such as $\mathrm{N}$. Africa and $\mathrm{N}$. Iran.

\section{References}

Benson, M. 1966. Studies in epidermal morphology in subspecies of Dactylis glomerata L. M. Sc. Thesis, Univ. of Wales.

Carroll, C. P. and Borrill, M. 1965. Tetraploid hybrids from crosses between diploid and tetraploid Dactylis and their significance. Genetica 36: 65-82.

Jones, K. and Borrill, M. 1962. Chromosomal status, gene exchange and evolution in Dactylis. 3. The role of the interploid hybrids. Genetica 32: 296-322.

-, Carroll, C. P. and Borrill, M. 1961. A chromosome atlas of the genus Dactylis L. Cytologia 26: 333-343.

Parker, P. F. and Borrill, M. New subspecies of Dactylis glomerata L. (in preparation).

Stebbins, G. L. and Zohary, D. 1959. Cytogenetic and evolutionary studies in the genus Dactylis. 1. Morphology, distribution, and inter-relationships of the diploid subspecies. Univ. Calif. Publ. Bot. 31: 1-40.

Zohary, D. and Nur, Uzi. 1959. Natural triploids in the orchard grass, Dactylis glomerata L., polyploids complex and their significance for gene flow from diploid to tetraploid levels. Evolution 13: 311-317. 